\title{
Why do cholestatic patients itch?
}

\section{The pruritus of cholestasis}

Pruritus is a distressing symptom that often complicates the syndrome of cholestasis in patients with hepatobiliary disorders. The pruritus of cholestasis may have a severe adverse impact on a patient's quality of life. It may not only interfere with normal activities but may lead to sleep deprivation and suicidal ideation. This form of pruritus can be an indication for liver transplantation. Gastroenterologists confronted with this problem often find themselves impotent and frustrated by the inadequacy of the options available to try and provide a patient with any substantial relief. Heroic measures (for example, charcoal haemoperfusion, partial external diversion of bile) have been tried, showing that conventional antipruritic treatments are not consistently efficacious. As long as treatments remain empirical, lacking any sound rationale based on an understanding of pathogenic mechanisms, treatment of this maddening condition will probably remain fundamentally unsatisfactory.

Cholestasis is characterised by an accumulation in plasma of substances, such as bilirubin, cholesterol, and bile acids, which under normal circumstances are efficiently secreted into bile. It has been conventional to assume that some of these retained substances are pruritogenic and that the pruritus of cholestasis arises as a consequence of an interaction between one or more of them (for example, bile acids) and nerve endings in the skin. Factors responsible for initiating pruritus in itchy skin disorders are assumed to act locally at the site of skin lesions. However, pruritus in cholestatic patients is not localised to skin lesions that may uncommonly arise as a consequence of the cholestatic process (for example, xanthomas). Indeed, the typical patient with the pruritus of cholestasis has no clinical evidence of a primary pruritic skin lesion, although secondary lesions (excoriations and prurigo nodularis caused by scratching) may develop. Furthermore, the assumption that the site of the primary event in the initiation of the pruritus of cholestasis is peripheral within the skin is not supported by convincing data.

\section{Pruritus of central origin}

It is clear from the neurological, psychiatric, and pharmacological literature that pruritus can arise centrally in the brain. As there is no evidence of any major neurological or psychiatric disorder associated with the pruritus of cholestasis, it may be pertinent to ask whether the mechanism of the pruritus of central origin to which pharmacology texts allude has any potential relevance to the pruritus of cholestasis. This mechanism seems to entail the interaction between opioid agonists; such as morphine, and opioid receptors in the central nervous system. Thus, 'pruritus may, in part, involve effects of opioids on neurons, since it is provoked by opioids that do not release histamine and is quickly abolished by small doses of (the opiate antagonist) naloxone' 1 and 'central modulators of pruritus, such as systemic morphine, cause itch ... by acting on central opiate receptors'. ${ }^{2}$ Indeed, 'itching' has been classified as an effect of morphine on the central nervous system. ${ }^{3}$ The concept that opioid agonists can induce pruritus by a central mechanism is highlighted by experiments in which potent opiates were given centrally. For example, when morphine $(0.2-0.5 \mathrm{mg} / \mathrm{kg})$ was injected intracisternally into cats violent facial scratching activity was induced that lasted for about 90 minutes, ${ }^{4}$ and when morphine (1-10 $\mu \mathrm{g}$ ) (but not saline) was injected into the medullary dorsal horn of monkeys naloxone reversible facial scratching occurred. ${ }^{5}$ Thus, increased central opioid mediated neurotransmission/neuromodulation (opioidergic tone) induced by opiates is associated with pruritus. Accordingly, increased opioidergic tone may contribute to the pruritus of cholestasis.

\section{The opioid system in cholestasis}

Five lines of evidence have emerged which, when considered together, strongly support the concept that cholestasis is associated with increased opioidergic tone. (1) A transient reaction, which has features in common with the withdrawal reaction of opiate addiction, has been seen after the oral administration of the potent opiate antagonist nalmefene (for example, $5 \mathrm{mg}$ ) to patients with chronic cholestatic liver disease. A similar reaction did not occur when high doses (for example, $300 \mathrm{mg}$ ) of nalmefene were given to normal subjects. ${ }^{6}$ (2) Analgesia (antinociception), a classic effect of opiates, occurs in an animal model of cholestasis and is reversed by (-)-naloxone (but not by its pharmacologically inert enantiomer (+)-naloxone)..$^{7}$ (3) Endogenous opioids accumulate in cholestasis. ${ }^{6} 8$ (4) Plasma extracts from patients with the pruritus of cholestasis (but not non-pruritic cholestatic controls) induce naloxone reversible facial scratching in monkeys when injected into the medullary dorsal horn, ${ }^{9}$ suggesting that plasma of patients with the pruritus of cholestasis contains an opioid substance that induces opioid receptor-mediated scratching activity of central origin. (5) The density of mu-opioid receptors in the brain is reduced in a model of cholestasis. ${ }^{10}$ Down regulation of central opioid receptors may occur in response to increased availability of endogenous opioids at opioid receptors in cholestasis.

\section{Effects of opiate antagonists on the pruritus of cholestasis}

The possibility that opiate antagonists may ameliorate the pruritus of cholestasis was first suggested by a case report published in $1979 .{ }^{11}$ Recently, by application of a monitoring system that objectively quantitates scratching activity independent of limb movements, mean scratching activity in eight pruritic patients with cholestasis resulting from primary biliary cirrhosis was shown in a single blinded trial to be $50 \%$ less during naloxone infusions than during placebo infusions. ${ }^{12}$ This effect of naloxone was subsequently confirmed by the results of a double blind placebo 
controlled trial in which 29 pruritic patients with cholestasis caused by several different liver diseases were enrolled. ${ }^{13}$ Furthermore, in the double blind trial the mean value for a visual analogue score of the perception of pruritus was significantly less during naloxone infusions than during placebo infusions. ${ }^{13}$ Thus, both the perception of pruritus and scratching activity in patients with the pruritus of cholestasis can be ameliorated by an opiate antagonist. In contrast with naloxone, nalmefene is efficacious as an opiate antagonist when given orally. In one open label trial subjective assessments of pruritus suggested that nalmefene given orally may be associated with a sustained amelioration of pruritus in cholestatic patients. ${ }^{6}$ In another open label trial quantitative data on scratching activity and visual analogue scores of pruritus also suggested that oral nalmefene induced sustained beneficial effects in most patients with unrelieved pruritus secondary to cholestatic liver disease. ${ }^{14}$ The validity of these inferences has been confirmed in a randomised, blinded, placebo controlled trial. ${ }^{15}$

\section{Concluding perspectives}

Increased opioidergic neurotransmission/neuromodulation (tone) in the central nervous system seems to contribute to the pruritus of cholestasis. Only interactions between certain opioid peptides and certain opioid receptor subtypes may be relevant to this phenomenon. Both the nature and source of the endogenous opioid peptides involved in this pathogenic mechanism are currently unknown, but one source may be the cholestatic liver itself. ${ }^{16}$ The new findings implicate a specific class of substances, endogenous opioids, and abnormal neurotransmission/neuromodulation in the brain in the pathogenesis of the pruritus of cholestasis. They also provide a rationale for giving orally bioavailable opiate antagonists to obtain longterm relief from this form of pruritus. In addition, these findings make it necessary to consider the possibility that cholestasis-related changes in the opioid system may lead to changes in other neurotransmitter systems and that such secondary changes might be responsible for a contribution to the pruritus of cholestasis in addition to that from changes in the status of the opioid system alone. For example, it is conceivable that altered serotoninergic neurotransmission might contribute to the pruritus of cholestasis. ${ }^{17}$ Like the opioid system, the serotonin system has been reported to modulate nociception (the perception of pain) in rats ${ }^{18}$ and, hence, may also modulate the perception of pruritus. Indeed, anecdotal reports ${ }^{19-21}$ and a placebo controlled (but not double blind) trial ${ }^{22}$ suggest that the 5-HT3 serotonin receptor antagonist ondansetron may ameliorate the pruritus of cholestasis. However, at the time of writing, no data that show definitively that serotoninergic neurotransmission is abnormal in cholestasis have been reported.

There is currently a paucity of data that show that peripheral events (in the skin) initiate the pruritus of cholestasis. Nevertheless, a contribution to pathogenesis from neural events originating in peripheral cutaneous nerve fibres cannot be excluded. However, there is now evidence that strongly suggests that cholestasis-related abnormal neurotransmission/neuromodulation in the central nervous system plays a part in the mediation of the pruritus of cholestasis.

Department of Gastrointestinal and Liver Diseases,

E A JONES

Academic Medical Centre,

Amsterdam

Division of Gastroenterology,

N V BERGASA

Department of Medicine,

Beth Israel Medical Center,

New York, USA

Correspondence to: Dr E A Jones.

1 Jaffe JH, Martin WR. Opioid analgesics and antagonists. In: Gilman AG, Rall TW, Nies AS, Taylor P, eds. Goodman and Gilman's the pharmacological basis of therapeutics. 8th ed. New York: Pergamon Press, 1990: logical basis $485-521$.

2 Parker F. Skin diseases. In: Wyngaarden JB, Smith LH Jr, Bennett JC, eds. Cecil textbook of medicine. 19th ed. Philadelphia: WB Saunders, 1992: 2280-330.

3 Dollery C. Morphine. In: Dollery C, ed. Therapeutic drugs. Vol 2. New York: Churchill Livingstone, 1991: M225-33.

4 Koenigstein H. Experimental study of itch stimuli in animals. Arch Dermatol Syph 1948; 57: 828-49.

5 Oliveras J-L, Maixner W, Dubner R, Bushnell MC, Kenshalo DR Jr, Duncan GH, et al. The medullary dorsal horn: a target for the expression of opiate effects on the perceived intensity of noxious heat. $\mathcal{f}$ Neurosci 1986; 6: 3086-93.

6 Thornton JR, Losowsky MS. Opioid peptides and primary biliary cirrhosis. $B M F$ 1988; 297: 1501-4.

7 Bergasa NV, Alling DW, Vergalla J, Jones EA. Cholestasis in the male rat is associated with naloxone-reversible antinociception. $\mathcal{F}$ Hepatol 1994; 20: 85-90.

8 Swain MG, Rothman RB, Xu H, Vergalla J, Bergasa NV, Jones EA. Endogenous opioids accumulate in plasma in a rat model of acute cholestasis. Gastroenterology 1992; 103: 630-5.

9 Bergasa NV, Thomas DA, Vergalla J, Turner ML, Jones EA. Plasma from patients with the pruritus of cholestasis induces opioid receptor-mediated scratching in monkeys. Life Sci 1993; 53: 1253-7.

10 Bergasa NV, Rothman RB, Vergalla J, Xu H, Swain MG, Jones EA. Central mu-opioid receptors are down-regulated in a rat model of acute mu-opioid receptors are down-regulat

11 Bernstein JE, Swift R. Relief of intractable pruritus with naloxone. Arch Dermatol 1979; 115: 1366-7.

12 Bergasa NV, Talbot TL, Alling DW, Schmitt JM, Walker EC, Baker BL, et al. A controlled trial of naloxone infusions for the pruritus of cholestasis. Gastroenterology 1992; 102: 544-9.

13 Bergasa NV, Alling DW, Talbot TL, Swain MG, Yurdaydin C, Turner ML et al. Effects of naloxone infusions in patients with the pruritus of cholestasis: a double-blind randomized controlled trial. Ann Intern Med 1995; 123: 161-7.

14 Bergasa NV, Alling DW, Talbot TL, Schmitt JM, Fong T-L, Fried MW, et al. Relief from the intractable pruritus of chronic cholestasis associated with oral nalmefene therapy. Hepatology 1991; 14: 154A.

15 Bergasa NV, Alling DW, Talbot TL, Chia SC, Souppaya M, Conjeevram $\mathrm{H}$, et al. Nalmefene therapy is associated with the relief of the pruritus of cholestasis: results of a double-blind randomised placebo-controlled trial. cholestasis: results of a double-
Hepatology 1993; 18: 177A.

16 Bergasa NV, Sabol SL, Young WS III, Kleiner DE, Jones EA. Cholestasis is associated with preproenkephalin mRNA expression in the adult rat liver. Am ₹ Physiol 1995; 268: G346-54.

17 Schworer H, Ramadori G. Cholestatischer pruritus - Pathophysiologie und therapie unter besonder berucksichtigung der behandlung mit 5-hydroxytryptamin-subtyp-3-rezeptor-antagonisten. $Z$ Gastroenterol 1995; 33: 265-74.

18 Richardson BP. Serotonin and nociception. Ann NY Acad Sci 1990; 600: 511-20.

19 Schworer H, Ramadori G. Treatment of pruritus: a new indication for serotonin type 3 receptor antagonists. Clin Investig 1993; 71: 659-62.

20 Schworer H, Ramadori G. Improvement of cholestatic pruritus by ondansetron. Lancet 1993; 341: 1277.

21 Raderer M, Muller C, Scheithauer W. Ondansetron for pruritus due to cholestasis. N Engl $\mathcal{F}$ Med 1994; 330: 1540.

22 Schworer H, Hartmann H, Ramadori G. Relief of cholestatic pruritus by a novel class of drug: 5-hydroxytryptamine type 3 (5-HT3) receptor antagonists; effectiveness of ondansetron. Pain 1995; 61: 33-7. 